\title{
RFID BASED STUDENT'S BUS MONITORING SYSTEM
}

\section{S. UMA \& R. BHUVANYA}

Assistant Professor, Department of CSE Assistant Professor, VELTECH DR RR \& DR SR UNIVERSITY Chennai, Tamilnadu

This work aims at designing a student monitoring system which could effectively manage presence of students at school buses. Student's presence is marked after each student's identification. For the identification of student, a RFID based system is used. RFID method is considered to be the best and fastest method for identification. So, the framework is developed for managing the student's attendance. RFID reader is placed in the school bus, hence whenever the student boards into the bus, the students have to place their RFID tag to indicate the presence of arrival and departure. This RFID reader takes attendance electronically, and the records of the attendance are sent digitally to the school database. The database in turn generates a text message and sends it to the corresponding parents indicating the safer departure and arrival time of their children.
\end{abstract}

KEYWORDS: RFID Method, Records of the Attendance \& Departure and Arrival Time

Received: Nov 17, 2017; Accepted: Dec 03, 2017; Published: Jan 05, 2018; Paper Id.: IJMPERDFEB201822

\section{INTRODUCTION}

In schools and organizations we are giving much importance to the attendance during start and end of the day to mark a person's presence. Traditional ways of taking attendance is like recorded manually in attendance register by calling out names but this result in waste of time and human effort. And also there is a possibility of fraudulent issues that may happen while the people work with the register. And these fraudulent issues will be high when the class strength is more. A solution to overcome this problem is by using the system that will record the student's attendance based on RFID recognition. In this direction this

Paper suggests the method to record the student attendance automatically. This system consists of a RFID device in the school bus that helps for identifying the student. And this RFID reader will recognize the students based on the intelligent barcode present. This proposed method not only helps the educational institutions to mark the presence of students but also help the parents to inform about the safest arrival of their children in the morning. While in evening, if the barcode is recognized then the parents will get a text message about the departure time of their children. Hence the usage of this system will reduce the parent's tension towards their children.

RFID based attendance systems are in wide use for the unique identification of humans, especially for the purpose of verification and identification. It can do the process of automatic identification and collection of data from the database which ensures accurate and timely process. Though it is not a new technology it gained more attention in computing fields since it uses the combination of radio frequency and microchip technologies that creates a system for identification. [1]

RFID belongs to a group of ADC termed as Automatic Identification and Data Capture. This method helps to identify the objects automatically with little or no human intervention. It consists of components like 
RFID tag, smart label, RFID reader and an antenna. RFID tag has an integrated circuit and an antenna that helps for the transmission of data to the RFID reader. The reader then converts the radio waves to a usable form of data. Now the collected information from the tags is sent to a computer system through a communication interface which can be stored in a database and can be analyzed at a later time.

RFID is emerging as an increasingly common scanning technology in countless industries simultaneously. RFID tags can be classified based on the Tag Transmission, frequency and by read distance. Tag Transmission is further divided into Active and Passive tags. For Item and personal identification, passive tags play an active role whereas for vehicle identification in toll gate active tags helps accordingly. Based on the frequency, RFID tag is classified as Low Frequency $(125-134.2 \mathrm{KHz})$, High Frequency (13.56 MHz) and Ultra High Frequency (956 MHz). Finally based on the read distance it is further divided into Near field( Less than 1 inch range), Mid Range( 1 to 10 foot read distance) and Long Range( 10 to 300 read distance)

In a human resource management system, attendance management is a major part. Hence punctuality and regular attendance are expected from all students in the institutions. Purpose of the attendance is very important since it will be used for the record keeping, assessment of students and that will act as a indirect loop hole of knowledge acquiring. In a traditional method the use of sheets of paper or books are used in taking attendance presents. But there is a possibility for impersonation and the attendance sheet could be stolen or lost. Taking attendance is a time consuming process, and also it is difficult to ascertain the parents about the safety departure and arrival time of a student. Thus the system is designed to mark the presence of students with their earliest and safest reach ability. This is why the RFID reader is placed in the school bus.

Here we used the passive RFID tags. It has no on-tag power supply and it has two important components namely tag's antenna and the micro chip or integrated circuit (IC). This common structure is referred as RFID inlay. Passive tags fall into two categories said to be inlays or hard tags. Hard tags are durable and made of plastic, metal, ceramic and even rubber. These tags come in all shapes and sizes and designed for a unique function.

\section{RELATED WORK}

In [1] author describes the attendance management system based on the fingerprint verification. Verification of the intended person can be done based on minutiae extraction on the ridges. Then the identification process is carried out by comparing the captured finger print images against the stored template in the database. Then it signals the result true or false based on the logical result of person's authenticity.

In [2] the idea behind the attendance management system is, the student's attendance will be marked without the need to show their ID cards. But it requires several UHF readers to be placed in every class room which would result in expensive. So the system is implemented with RFID reader and passive tags, where the attendance of the particular student will be marked when the id card is shown in front of the RFID reader. And the idea is to record the attendance and maintain the report automatically.

An NFC supported Attendance system in a University Environment is introduced in [3]. NFC technology can also be used in online payment, access control and user identification. Here the NFC enabled mobile devices and tags acts as reader unit. And this unit is responsible for collecting student ID form NFC enabled mobile device or tag. Device ID is the one that is used to verify the student. This system is said to be comparatively advantageous because of the minimal 
hardware requirements.

A new system is introduced for automated attendance entry in [4]. The attendance can be automated for students via NFC and Face Recognition. Manual attendance calculation will usually take lot of time. And certain amount of proxies will be recorded. The use of NFC will mark the attendance robotically when the student's card is passed through the reader and the use of face recognition will assist in validating student which ensures the avoidance of proxies.

[5] Emphasizes on smart, location based time and attendance tracking system using android application. Any employee who crosses the area border with a smart phone will be tracked automatically. This location based attendance tracking system will mark the login and logout based on the location. Whenever the employee enters his workplace area server gets the local time captures the employee id and the information will be stored in the database. Whenever the employee leaves the office area the system notifies the employee is leaving and it will be updated in the office server. To run the whole system it is important that both the employee device and the office server is in the same internet connection.

\section{SYSTEM DESIGN}

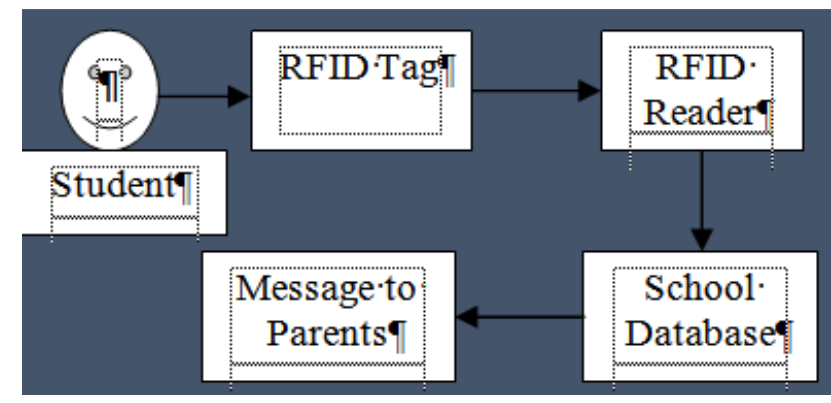

\section{IMPLEMENTATION}

RFID based attendance management system has the following working procedure.

- RFID Reader

- Data Retrieval

- System database

- Transmission of text message

\section{RFID Reader}

RFID tags are of two types: Active and passive. Tags that contain their own power source are known as active tags. But those without any power source are said to be passive tags. When compared with the memory active tags have higher memory and it can be read at greater ranges. In general active tags can be powered in battery and it will actively transmit a signal in the longest read range of 100 meters. Comparatively it is expensive due to the battery and transmitter cost. Here we used the passive tag to get the data transmitted. It reacts to the signals from the reader or writer or interrogator which in turn conveys signals to the computer.

Here the components that we used are Arduino, RFID Reader, RFID Tags and Mobile phone of laptop. Every student in the school is assigned with a unique RFID number. RFID reader is placed in the bus and this reader combines 
the function of transmitter, receiver and data interface. When the student enters the bus he/she can mark their presence by scanning the RFID tag given to them and the unique ID embedded in that will be recognized by the RFID reader. Here the receiver reads the tag's response and as soon as the ID is recognized by the reader the interface passes the attendance information to a server.

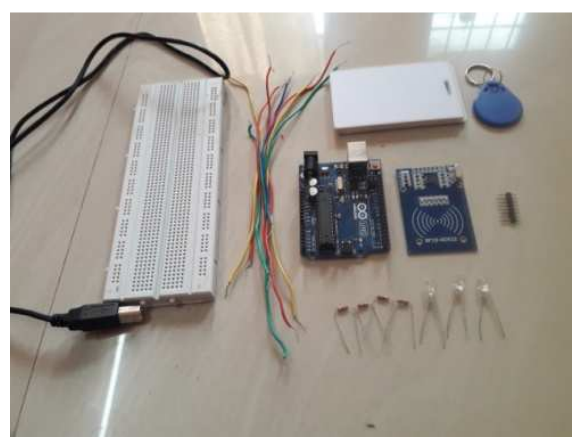

Figure 1: Component Used

\section{Data Retrieval}

Server picks up the data sent to it by the RFID reader. Then the computer finds the tag's record in a database and marks the record as "received". When the status is updated in the database the server will retrieve the student's information like ID, Parents name and contact number. Marked attendance along with the arrival time will be sent as a text message to the parent's contact number in the morning. Similarly when the student boards onto the bus in the evening, again the RFID tag has to be activated to indicate the leaving time. As soon as the departed time is indicted in the database during the evening session again their parents will receive the text message of their children arrival.

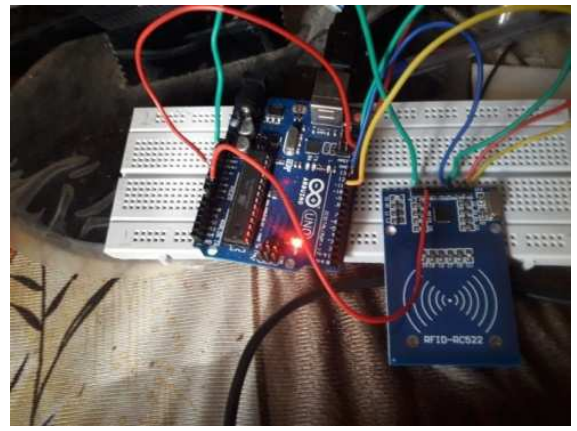

Figure 2: Arduino with RC522

As indicated in the above figure 2, RFID reader will check the RFID tag and verifies the name of the student that is saved in the student's database and the communication will be sent to the concerned parents.

\section{System Database}

School database is created and maintained by administrator. Here the database comprises of Student's name, student ID, Class, Section, Passport Photograph, parents phone number, address. Whenever the student's name is recognized the parents will receive the text message of safer arrival/ departure of their children. The transmission of text message can be done by retrieving the parents phone number from the database stored. The database is designed with the structured query language (SQL). With this we can retrieve the large amount of records from a database quickly and efficiently. It is the database language which is used widely in business and enterprise applications throughout the globe. Specifically to work with the enterprise applications, it is a perfect language for database. Previously SQL databases were 
synonymous with the relational database. Now with the evolution of OODBMS object storage capabilities are extended to relational database.

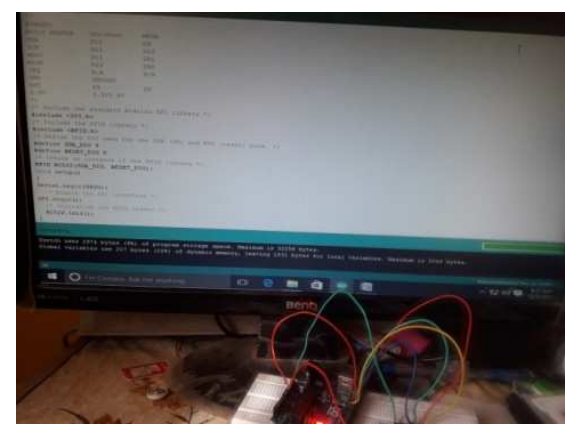

Figure 3: Arduino Connected to System

\section{Transmission of Text Message}

This elaborately explains the transmission of text message to an appropriate phone number stored in the database. Here every student's ID is mapped with their parent's phone number. When the ID is matched then the particular phone number will be identified through the school database and the text message will be forwarded to the parents. With this the parents can feel secured about their children and they can calculate the arrival time to their home when the departure time of their children is sent. And also the parents can feel relaxed hence they can get to know about their children in the morning and in the evening. So there is no way of missing the child. And this RFID based attendance system eliminates the traditional way of taking attendance and the student's attendance can also be calculated easily.

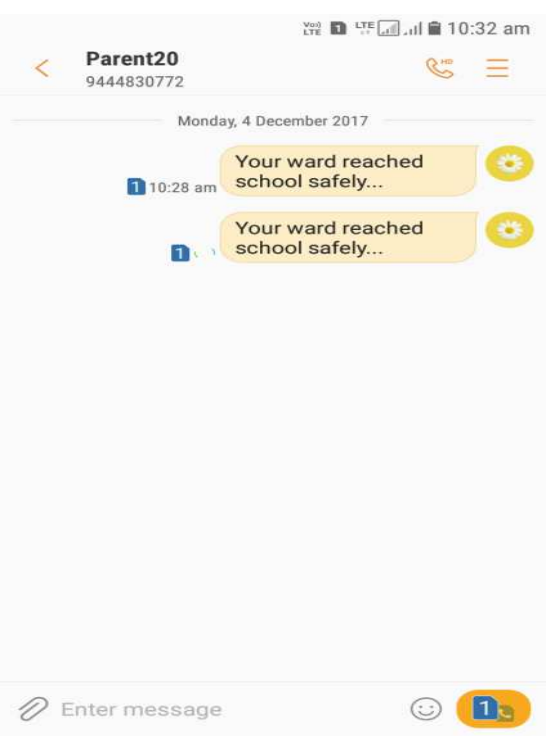

Figure 4: Text Message to Parents

\section{CONCLUSION AND FUTURE SCOPE}

With the secure schooling using RFID we can conclude that the students will reach their destination safely. Since the parents are aware of the departure and arrival timings, no one can get away from their respective destination. And also the implementation of this RFID eliminates the way if taking attendance by calling out the student's name. Thus it saves the faculty member's time and energy. It can be further enhanced by marking the attendance of the students with the biometric recognition 


\section{REFERENCES}

1. Shashank Shukla, Shailee Shah, Pooja Save: “RFID Based Attendance Management System”, International Journal of Electrical and Computer Engineering (IJECE), Vol. 3, No. 6, December 2013, pp. 784 790

2. Ashwin.K, AswinPerumal.A, Krishnakumar, Maheswari M "RFID Based Student Attendance and Monitoring System", International Journal of Innovative Research in Computer and Communication Engineering, Vol.3, Special Issue 1, February 2015

3. Media Anugerah Ayu, Member, IACSIT and Barroon Ismaeel Ahmad, "TouchIn: An NFC Supported Attendance System in a University Environment”, International Journal of Information and Education Technology, Vol. 4, No. 5, October 2014.

4. Sankul Rathod, Priyanka Shirsat, Vaibhav Thorat, Tejaswini Panure "Smart Attendance System using NFC and Face Recognition”, International Research Journal of Engineering and Technology (IRJET), Volume: 03 Issue: 11 | Nov -2016

5. Shermin Sultana, Asma Enayet and Ishrat Jahan Mouri "A smart, location based time and attendance tracking system using android application”, International Journal of Computer Science, Engineering and Information Technology (IJCSEIT), Vol. 5,No.1, February 2015 